\title{
The evidence debate
}

\section{V McQueen}

\section{Evaluating evidence for public health interventions}

$\mathrm{T}$ his issue presents an excellent article from Australia addressing the criteria for evaluating evidence for public health interventions. ${ }^{1}$ This article should be read within the context of the evidence debate that occupied the last decade of the 20th century and continues into the present. The origins of this debate are found in a clinical medicine that sought to establish a dialogue on evidence-based medicine. ${ }^{2}$ Gradually this debate has been extended to public health, health promotion and community-based public health interventions. The assumption of many in public health is that this is an important, vital debate, that is necessary to demonstrate what constitutes evidence and therefore proof that public health interventions are effective. The application of evidence criteria has taken much public health evaluation down a path implying scientific rigor. Evidence as a topic may be debatable, but arguably most public health practitioners feel a strong need to either justify their actions or demonstrate to others that their field of application is one with tangible benefits to the public. ${ }^{3}$ Still, there are many, particularly in health promotion who believe that "evidence", the very word, is inappropriate in evaluating much of public health practice.

What is most useful about the evidence debate is how it has served to broaden the discussion on evaluation of community-based public health interventions. Today, perhaps more than ever, public health practitioners are aware of the social and cultural context in which they carry out their work. This awareness applies at all levels of society. At the local level we are sensitised to local needs and public understandings of health. At the global level we recognise the incredible diversity of nations in terms of economic development and cultural beliefs. Despite this accepted awareness of the great diversity in populations, some may still hold the belief that the evidence discussion is not affected by the contextual diversity However, those who have been engaged in the evidence debate now recognise that the cultural bias of the evidence discussion must be taken into consideration. Notions such as "evidence", "effectiveness," "investment," "stakeholder," are rightly viewed as Western derived, European-American, and in many ways Western concepts. These concepts developed largely out of Western philosophical writings of the past two centuries and the epistemological underpinnings fostered by the development of logical positivism. ${ }^{4}$ The idea of evidence emerging from experimental design is a historical product of this development, with the randomised controlled clinical trial and the quasiexperimental approach largely creations of a Western literature. ${ }^{5}$ These approaches are widely accepted and almost universally applied in the physical and biological sciences, however, in the social and behavioural sciences their acceptance is less universal. Many social sciences have alternative, but none the less Western, approaches to assessing usefulness and effectiveness of interventions. To the extent that public health is a mixture of science, practice, and intuitive application and uses a mixture of approaches, it is problematic to define accurately the meaning of an evidence-based approach given the broad spectrum of public health actions that range from disease control to health policy. ${ }^{6}$

The Western bias in the debate is exacerbated by a dependence on published literature as a source for evidence. Material that might enhance the debate from a non-Western perspective is largely unpublished. Furthermore, even in the published literature there is attention lacking to the issue of transferability so cogently discussed in the paper by Rychetnik and colleagues. Most of the extant literature has paid scant attention to the social context of interventions that are evaluated. In part, this is a result of the lack of traditional positivistic evaluation designs to place emphasis on the context of the intervention. This issue has been addressed critically in recent publications ${ }^{7}$ and it remains to be seen whether future efforts to extend the evidence debate will take up the challenge of transferability.

Fortunately, there are several recent and ongoing collective efforts to address the evidence debate for communitybased public health interventions. These have been discussed in some detail in the paper by Rychetnik et al and elsewhere. $^{13}$ In particular one should note the efforts of the United States and the Community Preventive Services Task Force as a model for an advanced industrialised economy with highly developed public health infrastructure. ${ }^{8}$

Some multinational efforts have produced interesting and important results, particularly two working groups assessing health promotion interventions. A multidisciplinary working group on health promotion evaluation consisting of representatives from Health Canada, CDC. WHO(EURO), and HEA discussed, in multiple meetings during 1995-1998, how policy makers view evidence. In the end a small pamphlet for policy makers was prepared and widely distributed. The full deliberations of this evaluation working group are now published in a scholarly monograph on evaluation. ${ }^{7}$

Recently, under the guidance of the International Union for Health Promotion and Education, an advisory group, produced a report for the European Commission on the evidence of health promotion effectiveness. ${ }^{9}$ The great value of this report, which should be required reading for those interested in the field of health promotion, is that it identifies a considerable body of evidence pointing to the value of health promotion and attesting to its effectiveness.

What characterises these efforts at a collective interpretation is their scale and complexity. They are the results of relatively large numbers of people working assiduously at their task, over considerable periods of time, often producing volumes of manuscripts and detailed analyses of extant literature. It is important to emphasise that these approaches are labour intensive; they require time, dedication and considerable funding.

The size and scope of Western efforts to carry out and continue the evidence debate raises a serious question for the economically developing world. Are there debates about the nature of evidence in the non-Western world to parallel those being pursued in the industrialised West? A few global meetings have begun to address this question. In Mexico City, at the 5th Global Conference on Health Promotion, efforts were made to bring all countries and perspectives into the debate. ${ }^{3}$ Members of an ad hoc working group on evidence called for a global workgroup responsible for creating a plan for the development of evaluation globally. More recently, international organisations such as WHO, PAHO and the IUHPE have taken up this charge to develop global standards for the evaluation of evidence in public health and health promotion interventions. It is early days; the challenges are great. It remains to be seen how the evidence debate will be carried out at the global level.

Epidemiol Community Health 2002;56:8384 


\section{Author's affiliations}

D V McQueen, National Center for Chronic Disease Prevention and Health Promotion, Centers for Disease Control and Prevention, 4770 Burford HWY, NE, Mailstop K-40, Atlanta, GA, 30341-3717, USA

Correspondence to: David V McQueen; dvmcqueen@cdc.gov

\section{REFERENCES}

1 Rychetnik L, Frommer M. Hawe $P$, et al. Criteria for evaluating evidence on public health interventions. J Epidemiol Community Health 2002;56:119-27.
2 Sackett DL, Straus SE, Richardson WS, et al. Evidence-based medicine; how to practice and teach EBM. Edinburgh: Churchill Livingstone, 2000.

3 McQueen DV, Strengthening the evidence base for health promotion. Health Promotion International 2001;11:261-8.

4 Suppe $\mathbf{F}$, ed. The structure of scientific theories. 2nd edn. Urbana, IL: University of Illinois Press, 1977.

5 Bhaskar R. A realist theory of science. New York: Verso, 1997.

6 Allison K, Rootman I. Scientific rigor and community participation in health promotion research: are they compatible? Health Promotion International 1996;11. 333-40.
7 Rootman I, Goodstadt M, McQueen DV, et al, eds. Evaluation in health promotion: principles and perspectives. Copenhagen: WHO Regional Publications, European Series, no 92, 2001

8 Briss PA, Zaza S, Pappaioanou M, et al, The Task Force on Community Preventive Services. Developing an evidence-based guide to community preventive services: methods. Am J Prev Med, 2000;18 (1S):35-43

www.thecommunityguide.org

9 IUHPE. The evidence of health promotion effectiveness: a report for the European Commission by the International Union for Health Promotion and Education.

Brussels-Luxembourg: ECSC-EC-EAEC, 1999

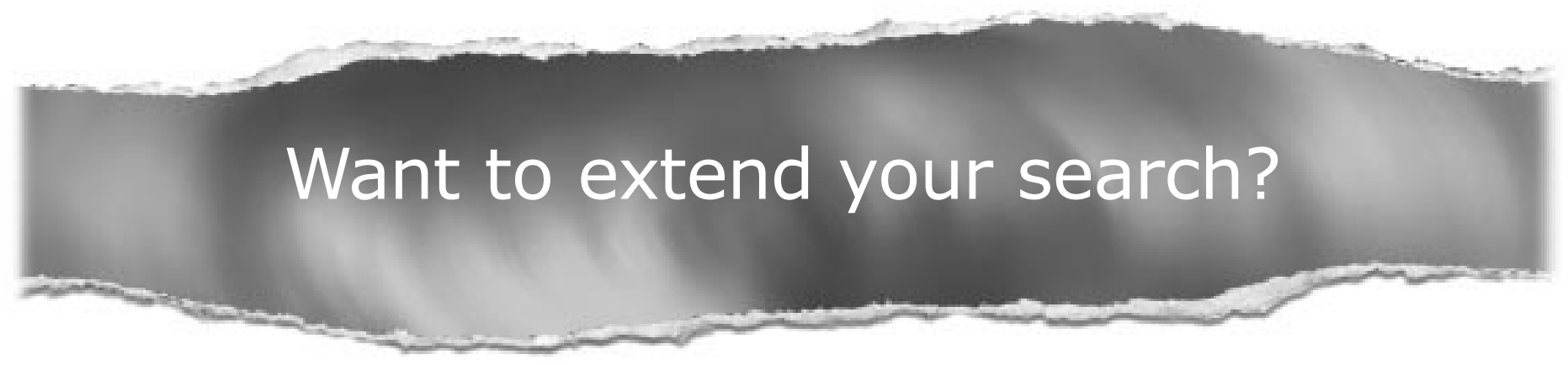

Cross journal searching

If you can't find what you are looking for in the Journal of Epidemiology and Community Health you can extend your search across many of the more than 200 journals available for selection. You can restrict your search to specific subject areas (eg, clinical medicine, basic research), or select specific journals, or search all available titles.

\section{www.jech.com}

